\title{
A rapid magnetic bead-based immunoassay for sensitive determination of diclofenac
}

\author{
Alexander Ecke ${ }^{1,2} \cdot$ Tanja Westphalen $^{1} \cdot$ Jane Hornung ${ }^{3} \cdot$ Michael Voetz $^{3} \cdot$ Rudolf J. Schneider $^{1,4}$
}

Received: 25 August 2021 / Revised: 18 October 2021 / Accepted: 5 November 2021 / Published online: 20 November 2021

(c) The Author(s) 2021

\begin{abstract}
Increasing contamination of environmental waters with pharmaceuticals represents an emerging threat for the drinking water quality and safety. In this regard, fast and reliable analytical methods are required to allow quick countermeasures in case of contamination. Here, we report the development of a magnetic bead-based immunoassay (MBBA) for the fast and cost-effective determination of the analgesic diclofenac (DCF) in water samples, based on diclofenac-coupled magnetic beads and a robust monoclonal anti-DCF antibody. A novel synthetic strategy for preparation of the beads resulted in an assay that enabled for the determination of diclofenac with a significantly lower limit of detection (400 $\mathrm{ng} / \mathrm{L})$ than the respective enzyme-linked immunosorbent assay (ELISA). With shorter incubation times and only one manual washing step required, the assay demands for remarkably shorter time to result $(<45 \mathrm{~min})$ and less equipment than ELISA. Evaluation of assay precision and accuracy with a series of spiked water samples yielded results with low to moderate intra- and inter-assay variations and in good agreement with LC-MS/MS reference analysis. The assay principle can be transferred to other, e.g., microfluidic, formats, as well as applied to other analytes and may replace ELISA as the standard immunochemical method.
\end{abstract}

Keywords Immunoassay $\cdot$ Magnetic beads $\cdot$ Diclofenac $\cdot$ Water analysis $\cdot$ LC-MS/MS

\section{Introduction}

The nonsteroidal anti-inflammatory drug (NSAID) diclofenac (DCF, Fig. 1) has been used frequently in the treatment of rheumatic diseases, inflammations, and fever, as well as acute and chronic pain since its introduction in the 1970s [1,2]. Together with ibuprofen and naproxen, DCF is among the most commonly sold non-aspirin NSAIDs in several countries worldwide over the past years [3,4]. Accordingly, the discharge of DCF via wastewater is relatively high considering

Rudolf J. Schneider

rudolf.schneider@bam.de

1 Department of Analytical Chemistry; Reference Materials, Bundesanstalt für Materialforschung und -prüfung (BAM), 12489 Berlin, Germany

2 Department of Chemistry, Humboldt-Universität zu Berlin, 12489 Berlin, Germany

3 sifin diagnostics gmbh, 13088 Berlin, Germany

4 Technische Universität Berlin, Faculty III Process Sciences, 10623 Berlin, Germany that the majority of orally administered DCF is excreted unaltered or metabolized via urine $(65-70 \%)$ or feces (20-30\%) and DCF applied cutaneously is mainly washed away $(>90 \%)[5,6]$.

Insufficient degradation in wastewater treatment plants (WWTPs) promotes introduction of DCF into surface waters where its ecotoxicological effects can lead to disruption of whole biosystems [6-12]. As a consequence, DCF has been proposed as a priority substance and was added to the EU watchlist for substances of concern requiring Union-wide monitoring in the field of water policy [13]. In this context, environmental quality standards for DCF in inland waters of $100 \mathrm{ng} / \mathrm{L}$ and $10 \mathrm{ng} / \mathrm{L}$ in all other surface waters were proposed [14]. The concentration values of DCF found in various surface waters, however, exceed these limits with values in the low $\mu \mathrm{g} / \mathrm{L}$ range reported for rivers in Europe, Asia, Africa, America, and even Antarctica (for a review, see [12]). As a result, DCF can also reach water bodies that are used for drinking water preparation which is highly alarming in concern of human health. So far, concentrations in the two- to three-figure ng/L-range are already found in many groundwater and drinking water samples [12]. Strategies for 
Fig. 1 Chemical structure of diclofenac (DCF)

is immobilized on the bead surface (direct approach) to set up a magnetic bead-based assay which is often more straightforward [39-42]. For some analytes, however, coupling of the analyte molecule to the particle surface (indirect approach) is more feasible [43-45]. For DCF, it could be mandatory. To date, no direct immunoassay for DCF has been reported. Concerning peroxidase-based immunoassays, the reason for this may lie in DCF's property of serving as a substrate for peroxidase [15]. Because a direct immunoassay for DCF would require an enzyme tracer, i.e., a conjugate of DCF coupled to peroxidase, this may be the main obstacle as the effects of coupling an enzyme to its substrate are not yet studied in detail.

This is why we chose an indirect approach to set up an MBBA for the quantification of DCF in water samples with the robust anti-DCF antibody F01G21 [24]. A novel synthetic strategy for DCF coupling to the bead surface was used to tune binding properties of the antibody in order to allow for a more sensitive detection. In combination with the advantages of magnetic particles, a fast and reliable immunoassay with potential for further application, e.g., implementation into an immunosensor, is presented.

\section{Materials and methods}

\section{General equipment}

Ultrapure water was taken from a Merck Millipore (Darmstadt, Germany) Milli-Q Reference water purification system. Weighing was performed on a Sartorius (Göttingen, Germany) Research R180D-*D1 or Cubis ${ }^{\circledR}$ Advanced MCA225S-2S00-I analytical balance. Adjustment of $\mathrm{pH}$ values was done with a SevenEasy pH meter S20 from Mettler Toledo (Columbus, OH, USA).

\section{Preparation of DCF-coupled beads}

Bead preparation and all related reactions were performed in 2-mL centrifuge tubes from Eppendorf (Hamburg, Germany). Shaking of reaction mixtures was executed in a ThermoMixer $\mathrm{C}$ from Eppendorf, and centrifugation was carried out using an Eppendorf Centrifuge 5417R. For washing, a BioMag® Multi-6 Microcentrifuge Tube Separator from Polysciences (Hirschberg an der Bergstraße, Germany) was used.

\section{NHS-activation of DCF}

As reported before [28], diclofenac sodium salt (SigmaAldrich, Steinheim, Germany) was dissolved in dry $N, N$ dimethylformamide (DMF, Sigma-Aldrich) under argon atmosphere to a final concentration of $1 / 6 \mathrm{~mol} / \mathrm{L}$. Stock 
solutions of $\mathrm{N}$-hydroxysuccinimide (NHS, Merck) and $N, N$ '-dicyclohexylcarbodiimide (DCC, Sigma-Aldrich) of $1 / 2 \mathrm{~mol} / \mathrm{L}$ each in DMF were prepared under argon. To the DCF solution, NHS solution (1.2 eq), a spatula tip of $N, N^{\prime}-$ disuccinimidyl carbonate (DSC, Sigma-Aldrich), and DCC solution (1.2 eq) were added in this particular order under argon. The resulting solution was shaken in the dark at RT and $750 \mathrm{rpm}$ for $18 \mathrm{~h}$.

Afterwards, the mixture was centrifuged at $4{ }^{\circ} \mathrm{C}$ and $4000 \mathrm{rpm}$ for $10 \mathrm{~min}$ in order to separate the precipitated dicyclohexylurea. The supernatant solution was used directly for coupling.

\section{Coupling to magnetic beads}

A suspension of amino-functionalized magnetic microparticles (Sigma-Aldrich, $100 \mu \mathrm{L}$ ) in $500 \mu \mathrm{L}$ absolute ethanol (Th. Geyer, Renningen, Germany) and $500 \mu \mathrm{L} 0.1 \mathrm{M}$ sodium bicarbonate (Sigma-Aldrich) was prepared. Consecutively, $100 \mu \mathrm{L}$ of a solution of $0.5 \mathrm{~mol} / \mathrm{L}$ glutaric anhydride (Merck) in absolute ethanol and $5 \mu \mathrm{L}$ of the above described DCF active ester solution were added. The resulting mixture was shaken at RT and $900 \mathrm{rpm}$ for $20 \mathrm{~h}$.

Thereafter, beads were washed once with Milli-Q water $(1 \mathrm{~mL})$ and thrice with absolute ethanol $(1 \mathrm{~mL})$ using a magnetic separator to hold the beads while removing the supernatant. Beads were then resuspended in absolute ethanol $(1 \mathrm{~mL})$ and stored at $4{ }^{\circ} \mathrm{C}$ until further use.

\section{Buffers}

All buffers were prepared in Milli-Q water and stored in amber glass bottles at room temperature (RT, $22 \pm 1{ }^{\circ} \mathrm{C}$ ) unless stated otherwise. The $\mathrm{pH}$ values were adjusted using $6 \mathrm{M}$ hydrochloric acid (Merck) or $5 \mathrm{M}$ sodium hydroxide solution (J.T.Baker, Phillipsburg, NJ, USA).

- Phosphate-buffered saline (PBS), pH 7.6: $10 \mathrm{mM}$ sodium phosphate monobasic dihydrate (Sigma-Aldrich), $70 \mathrm{mM}$ sodium phosphate dibasic dihydrate (Sigma-Aldrich), $145 \mathrm{mM}$ sodium chloride (Sigma-Aldrich).

- Washing buffer, pH 7.6: $0.75 \mathrm{mM}$ potassium phosphate monobasic (Sigma-Aldrich), $6.25 \mathrm{mM}$ potassium phosphate dibasic (Sigma-Aldrich), $0.025 \mathrm{mM}$ potassium sorbate (Sigma-Aldrich), 0.05\% Tween 20 (Serva, Heidelberg, Germany).

- Assay buffer (Tris-EDTA), pH 7.6, storage at $4{ }^{\circ} \mathrm{C}$ : $125 \mathrm{mM}$ tris(hydroxymethyl)-aminomethane (Tris, Merck), $187.5 \mathrm{mM}$ sodium chloride, $13.375 \mathrm{mM}$ ethylenediaminetetraacetic acid disodium salt dihydrate $\left(\mathrm{Na}_{2}\right.$ EDTA $2 \mathrm{H}_{2} \mathrm{O}$, Sigma-Aldrich).

- Citrate buffer, pH 4.0, storage at $4{ }^{\circ} \mathrm{C}: 220 \mathrm{mM}$ sodium citrate monobasic (Sigma-Aldrich).
- TMB stock solution in dry $N, N$-dimethylacetamide (DMA, Sigma-Aldrich), storage under argon at $4{ }^{\circ} \mathrm{C}$ : $8 \mathrm{mM}$ tetrabutylammonium borohydride (SigmaAldrich), 40 mM 3,3',5,5'-tetramethylbenzidine (TMB, Serva).

\section{Immunoreagents}

Polyclonal sheep anti-mouse $\operatorname{IgG}(\mathrm{H}+\mathrm{L}$ chain) antibody with horseradish peroxidase (HRP) label (secondary antibody, R1256HRP) was obtained from OriGene Technologies (Rockville, MD, USA). Mouse anti-DCF antibodies (isotype IgG1) F01G21 and SK60-2E4 were produced by fusion of mouse myeloma cells (AG8 [24] or SP2/0-AG14, respectively) and splenocytes from BALB/c mice, both obtained from the University of Salzburg [24].

The antibody F01G21 was further labeled with HRP using the periodate method as described by Wilson and Nakane [46]. Required chemicals sodium carbonate, sodium bicarbonate, and ammonium sulfate were from Carl Roth (Karlsruhe, Germany); sodium periodate and sodium cyanoborohydride from Sigma-Aldrich, ethylene glycol from Serva, and HRP from Roche (Basel, Switzerland). The antibody solution was concentrated to about $5 \mathrm{mg} / \mathrm{mL}$ in an Amicon ${ }^{\circledR}$ Stirred Cell Model 8010 (10 mL) equipped with an Ultrafiltration Disc (30 kDa) from Merck Millipore (Burlington, MA, USA). The labeling reaction was carried out in a glass vial equipped with a magnetic stirrer. The labeled antibody was purified in PBS using PD-10 or PD MiniTrap desalting columns with Sephadex G-25 resins from GE Healthcare (Chicago, IL, USA). Antibody concentration $(2.79 \mathrm{mg} / \mathrm{mL})$ and coupling ratio (2.65) were determined by UV/Vis absorption measurements in UV cuvettes micro from Brand (Wertheim, Germany) with a BioMate 3 UV-Vis Spectrophotometer from Thermo Fisher Scientific (Waltham, MA, USA). The product was stabilized with $0.04 \%$ thiomersal (Serva) and 2\% fetal bovine serum (Life Technologies, Carlsbad, CA, USA), and stored in aliquots at $4{ }^{\circ} \mathrm{C}$ for up to 1 month or at $-20{ }^{\circ} \mathrm{C}$ for long-term storage.

\section{Standards and samples}

Firstly, a stock solution of DCF-Na analytical standard (Sigma-Aldrich) in absolute ethanol with a mass concentration of approx. $1 \mathrm{~g} / \mathrm{L}$ was prepared gravimetrically by weighing both solid and the solvent. From this solution, serial dilutions in Milli-Q water were made volumetrically to prepare DCF standards in the concentration range from $10 \mathrm{mg} / \mathrm{L}$ to $1 \mathrm{ng} / \mathrm{L}$.

Spiked water samples were prepared by pre-diluting the stock solution of DCF-Na analytical standard in Milli-Q water and successive dilution in the respective sample to the 
desired concentration. Water samples were taken as specified in Table 1.

\section{Immunoassay procedure}

All assays were carried out in transparent 96-well flat bottom non-binding polystyrene microplates from Corning (Corning, NY, USA). Wells were filled using Eppendorf Research ${ }^{\circledR}$ pro multichannel pipettes. Dilutions were prepared with Eppendorf Research ${ }^{\circledR}$ plus piston stroke pipettes. Incubation was performed on a Titramax 101 orbital shaker from Heidolph Instruments (Schwabach, Germany). For washing, a BioMag ${ }^{\circledR}$ 96-Well Plate Separator from Polysciences was used. Absorbance measurements were carried out on a SpectraMax ${ }^{\circledR}$ Plus 384 or SpectraMax ${ }^{\circledR}$ i3x microplate reader from Molecular Devices (San José, CA, USA).

For one 96-well plate, $150 \mu \mathrm{L}$ of DCF-coupled beads suspension was mixed with $4.8 \mathrm{~mL}$ of assay buffer. A volume of $50 \mu \mathrm{L}$ of the resulting suspension was added to each cavity of the microplate. To this, $100 \mu \mathrm{L} /$ well of DCF standard solution or sample was added. The HRP-labeled mouse antiDCF antibody F01G21 was diluted in assay buffer to a concentration of $37.2 \mu \mathrm{g} / \mathrm{L}$, and $50 \mu \mathrm{L}$ of this solution was added to each well. Then, the resulting mixture was incubated at $\mathrm{RT}$ and $900 \mathrm{rpm}$ for $20 \mathrm{~min}$.

To remove unbound antibody, washing was performed by placing the microplate on a magnetic separator. After waiting for $120 \mathrm{~s}$ for the particles to separate from the suspension, the supernatant solution was carefully removed by gentle pipetting and replaced by $200 \mu \mathrm{L}$ of washing buffer. Subsequently, the plate was shaken for $30 \mathrm{~s}$ at $1050 \mathrm{rpm}$ for complete resuspension of the particles and the previous steps were repeated twice.

Still on the magnetic separator, $200 \mu \mathrm{L} /$ well of freshly prepared substrate solution $(22 \mathrm{~mL}$ citrate buffer, $8.5 \mu \mathrm{L}$ hydrogen peroxide solution (30\%, Sigma-Aldrich) and $550 \mu \mathrm{L}$ TMB stock solution) were added. After the addition was completed, the plate was shaken for $15 \mathrm{~min}$ at RT and $900 \mathrm{rpm}$ (1050 rpm for the first $30 \mathrm{~s}$ for resuspension of the beads). Blue color developed in wells with low concentration of DCF.
Color development was stopped by placing the plate on the magnetic separator and adding $100 \mu \mathrm{L} /$ well of $1 \mathrm{M}$ sulfuric acid (J.T.Baker) immediately. Color change from blue to yellow was observed. The plate was further shaken at RT and $750 \mathrm{rpm}$ for $30 \mathrm{~s}$, while particles remained separated on one side of the respective well.

Detection was performed by reading the optical density at $\mathrm{RT}$ at a wavelength of $450 \mathrm{~nm}$ with reference at $620 \mathrm{~nm}$. For calibration, O.D. values were plotted against the concentration of standard solutions and a four-parameter logistic function was fitted to the data points. Concentrations of samples (24 per plate, each analyzed in triplicate) were determined by correlating O.D. values to the respective concentration of DCF standards (8 per plate in triplicate).

\section{LC-MS/MS analysis}

LC-MS/MS measurements were carried out on an Agilent 1260 LC system from Agilent Technologies (Waldbronn, Germany) equipped with a binary pump (G1312B), column oven (G1316A), autosampler (G1367E), and a diode array detector (G1315D) coupled to a Triple Quad 6500 Mass Spectrometer from AB Sciex Instruments (Darmstadt, Germany). A Kinetex ${ }^{\circledR} 2.6 \mu \mathrm{m}$ XB-C18 $100 \AA$ LC column $(150 \times 3 \mathrm{~mm})$ from Phenomenex (Aschaffenburg, Germany) and a matching pre-column were used.

Each water sample was analyzed undiluted in duplicate with an injection volume of $10 \mu \mathrm{L}$ and the column oven temperature set to $55^{\circ} \mathrm{C}$. At a flow rate of $350 \mu \mathrm{L} / \mathrm{min}$, a binary gradient consisting of (A) water and (B) methanol (LC-MS grade, Biosolve, Valkenswaard, Netherlands) both containing $10 \mathrm{mM}$ ammonium acetate (Sigma-Aldrich) and $0.1 \%$ (v/v) acetic acid (Fluka, Buchs, Switzerland) was used under the following conditions: 70\% A isocratic for $3 \mathrm{~min}$; linear decrease to 5\% A within $9 \mathrm{~min}$; kept at 5\% A for $6 \mathrm{~min}$; increase to $70 \%$ A within $0.5 \mathrm{~min}$; kept at $70 \%$ A for $6 \mathrm{~min}$.

Electrospray ionization (ESI) was performed in positive mode at a source temperature of $400{ }^{\circ} \mathrm{C}$ and an ionspray voltage of $4500 \mathrm{~V}$. Gas pressures were applied as follows: curtain gas 35 psi, nebulizer gas 62 psi, turbo gas 62 psi, collision gas 8 psi. At an entrance potential of $10 \mathrm{~V}$, a

Table 1 Details on water samples and sampling procedure

\begin{tabular}{|c|c|c|c|}
\hline Sample & Sampling day & Sample description & Sampling site \\
\hline Pure water & 08.06 .2021 & From water purification system & BAM building 8.05 , room $395 \mathrm{C}$ \\
\hline Drinking water & 08.06 .2021 & From water cooler & BAM building 8.05 \\
\hline Mineral water & 09.06 .2021 & Bottled water, nonsparkling, Lichtenauer Pur, BBD: 31.08.21 & - \\
\hline Tap water & 08.06 .2021 & From laboratory water tap & BAM building 8.05, room 394 \\
\hline Groundwater & 07.06 .2021 & From water well with an electric pump & Groß-Kienitz, 15831 Blankenfelde-Mahlow \\
\hline Surface water & 08.06 .2021 & $\begin{array}{l}\text { From Teltowkanal (canal), filtrated through a } 0.45-\mu \mathrm{m} \\
\text { regenerated cellulose filter }\end{array}$ & Ernst-Ruska-Ufer, 12489 Berlin \\
\hline
\end{tabular}


declustering potential of $90 \mathrm{~V}$, a cell exit potential of $15 \mathrm{~V}$, and a dwell time of $100 \mathrm{~ms}$ for each transition, the mass transitions $\mathrm{m} / \mathrm{z} 296 \rightarrow 250$ and $\mathrm{m} / \mathrm{z} 296 \rightarrow 214$ with a collision

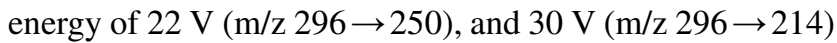
were used for quantification in selected reaction monitoring mode. For calibration, DCF standard solutions of eight different concentrations in the range from 0.2 to $100 \mu \mathrm{g} / \mathrm{L}$ including one blank were used.

Data acquisition and analysis were performed using the software Analyst 1.7.1 and Sciex OS- Q 1.4.1.20719 from AB Sciex.

\section{Results and discussion}

\section{Preparation of DCF-coupled beads}

Superparamagnetic amino-functionalized microparticles (BioMag ${ }^{\circledR}$ Plus) were coupled with DCF after activation of its carboxyl function via reaction with DCC and NHS. The DCF active ester readily reacts with amino functions on the particle surface, anchoring the DCF moieties via amide bonds. In a first binding test however, the so-prepared beads showed a very high background signal that could be ascribed to non-specific binding (NSB) of the antibody to excess free amino groups on the bead surface. The same was observed for the untreated particles.

In order to reduce NSB, amino functions were blocked by reaction with cyclic anhydrides, namely succinic anhydride (SA) or glutaric anhydride (GA). Binding tests with two different monoclonal anti-DCF antibodies (F01G21 and SK60-2E4) revealed that NSB was successfully blocked and binding of the antibodies to the DCF moieties was not impaired (Fig. S1).

Interestingly, the preparation of the beads had to be performed in a one-pot reaction with both DCF active ester and anhydride added at once (Fig. S2). Sequential reaction with DCF active ester and anhydride yielded beads that gave high NSB indicating that only the component added first is reacting. Accordingly, addition of anhydride before DCF active ester led to formation of beads which showed no binding of anti-DCF antibodies.

Besides that, incorporation of the $\mathrm{C}_{6}$ spacer 6-aminohexanoic acid (Ahx) between DCF and the bead surface ( $\mathrm{S} 0$ and Fig. S3) was tested as well but appeared to be unsuitable as binding of the anti-DCF antibodies was too strong and could only be inhibited by higher DCF concentrations for the antibody F01G21 (Fig. S4) or not inhibited by up to $10 \mathrm{mg} / \mathrm{L}$ DCF for SK60-2E4. On the other hand, the antibody SK60$2 \mathrm{E} 4$ showed consistently higher $\mathrm{IC}_{50}$ values for DCF beads (Fig. S5) showing the lower affinity of this antibody. Moreover, SK60-2E4 showed binding to beads that were coupled with Boc-protected Ahx which could be inhibited by high
DCF concentrations (Fig. S6) indicating lower specificity of that antibody. Against this backdrop, the following investigations were carried out with the antibody F01G21 only.

In a next step, the ratio of DCF active ester and anhydride added to the bead suspension was optimized to achieve the lowest limit of detection (LOD) in binding of dissolved DCF (from samples). It was found that lower amounts of DCF active ester lead to more reproducible results regarding maximum O.D. values after binding of the antibodies. Furthermore, a large excess of anhydride (50-100-fold) over DCF active ester yielded calibration curves with the lowest $\mathrm{IC}_{50}$ values at reasonable binding intensities. Comparing both anhydrides, beads that were blocked with GA yielded slightly lower $\mathrm{IC}_{50}$ values in calibration curves than those blocked with SA (Fig. 2a). Moreover, the advantage of using a blocking reagent as additional parameter for tuning the binding properties of the antibody could be demonstrated by coupling DCF to a different brand of beads (Dynabeads ${ }^{\mathrm{TM}}$ M-270 Amine). These did not require additional blocking as they did not show any NSB of the antibody. In fact, applying a blocking reagent together with DCF active ester prevented binding of anti-DCF antibodies to the beads completely. The unblocked beads, however, allowed binding but calibration curves obtained with these beads showed a significantly higher $\mathrm{IC}_{50}$ value than BioMag® Plus beads blocked with GA (Fig. 2b).

Finally, the optimized coupling ratios for reproducible preparation of the DCF-coupled beads were determined to be $0.5 \mu \mathrm{mol}$ DCF active ester and $50 \mu \mathrm{mol}$ GA per $100 \mu \mathrm{L}$ of bead suspension. Beads produced in this manner were used to set up the competitive immunoassay for determination of DCF in water samples.

\section{Building the competitive immunoassay}

Before setting up and optimizing the assay with the antibody F01G21, the recognition element was labeled with horseradish peroxidase (HRP) using a commercial labeling kit. With an achieved coupling ratio of 2.65 , the sensitivity of the assay could be increased drastically with lower amounts of antibody needed to obtain high signal intensities. Besides, the assay could be sped up as the additional incubation with a secondary antibody as well as the associated washing step could be omitted.

Assay conditions were optimized regarding the assay buffer, incubation time, amount of bead suspension, and antibody dilution. Regarding the assay buffer, it was found that a Tris-based buffer with EDTA at pH 7.6 was most suitable. While a change in buffer composition and $\mathrm{pH}$ did not lead to evident shifts of the calibration curve in terms of the $\mathrm{IC}_{50}$, the ratios of minimum and maximum O.D. varied distinctly with the broadest range observed for Tris-EDTA at pH 7.6 (Fig. S7a). Buffers PBS (pH 7.6) and Tris-EDTA 


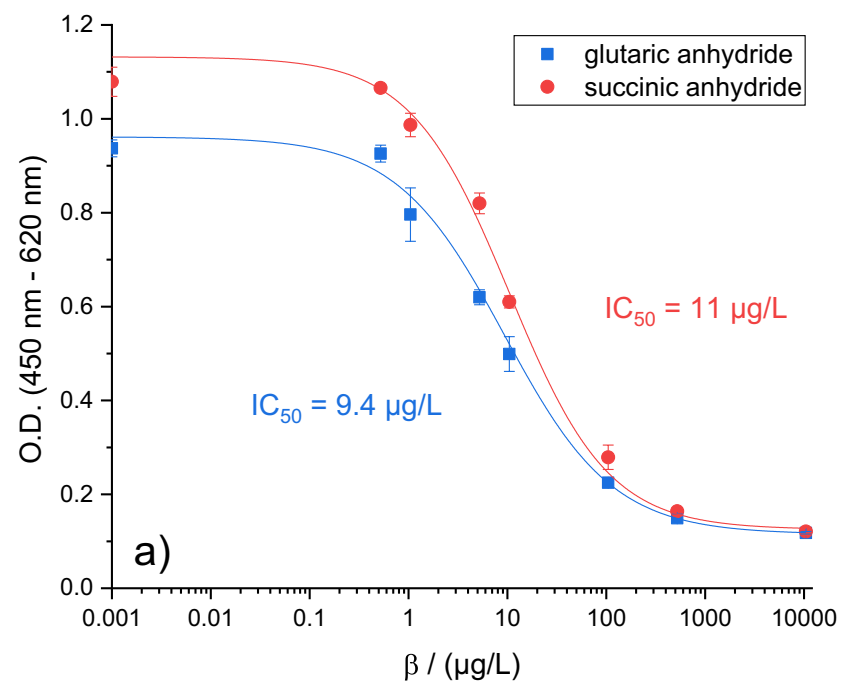

Fig. 2 Calibration curves obtained with differently prepared beads ( $n=3$, error bars represent single standard deviation). a Comparison of the two blocking reagents GA and SA applied together with DCF

(pH 8.5) gave the lowest background signal but also yielded very low maximum signal intensities, requiring more beads and/or antibody to be increased. Both would make the assay less cost-effective. A lower $\mathrm{pH}$ of 6.5 with PBS as a buffer did not seem reasonable as here the background signal was the highest of all tested buffers with the signal maximum well below that of Tris-EDTA (pH 7.6). For the purpose of analyzing water samples, the use of Tris-EDTA $(\mathrm{pH}$ 7.6) appeared further useful since the contained EDTA can reduce the impact on antibody binding by chaotropic ions like $\mathrm{Ca}^{2+}$ and $\mathrm{Mg}^{2+}$ which may be contained in higher concentrations in the samples.

The incubation time of the antibody with the sample and beads was found to be sufficient to reach a desired maximum O.D. of $1 \pm 0.1$ reproducibly after $20 \mathrm{~min}$ (Fig. S7b). Longer incubation times not only further increased the maximum intensity but also led to higher background signals from NSB. Therefore, and in the interest of short analysis times, incubation was stopped after $20 \mathrm{~min}$, and beads were washed to remove unbound antibody.

The antibody itself was diluted to a concentration of $9.3 \mu \mathrm{g} / \mathrm{L}$ which yielded reasonable signal intensities at sufficiently low $\mathrm{IC}_{50}$ values with an amount of $150 \mu \mathrm{L}$ of bead suspension per plate which corresponds to approximately 1.5 $\mu \mathrm{L}$ of bead suspension per well. All steps of the immunoassay procedure are illustrated in Fig. 3.

Under these optimized conditions, the measurement range of the assay was determined according to the rules to set up a precision profile described by Ekins [47] (Fig. 4). Correspondingly, DCF concentrations can be determined with an error of concentration below $30 \%$ in a range from $400 \mathrm{ng} / \mathrm{L}$ to $300 \mu \mathrm{g} / \mathrm{L}$. Compared to the previously reported ELISA

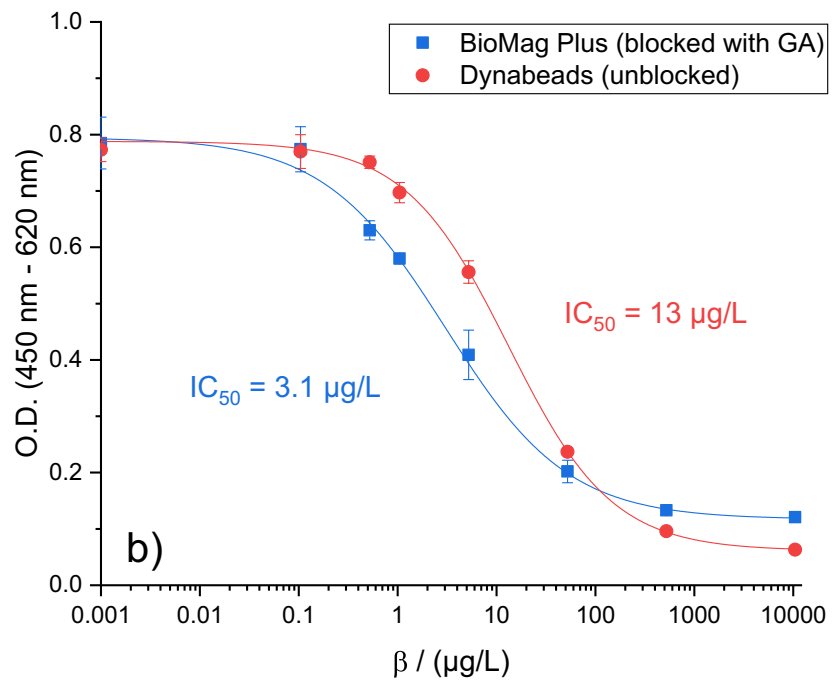

active ester on BioMag Plus ${ }^{\circledR}$ particles. b Influence of blocking comparing BioMag Plus ${ }^{\circledR}$ particles blocked with GA after further optimization and unblocked Dynabeads ${ }^{\mathrm{TM}}$

based on the same antibody [24, 25], this represents a clear improvement (measurement range: $3-150 \mu \mathrm{g} / \mathrm{L}$ ). With the LOD significantly reduced and the analytical range broadened, the newly developed assay is more versatile and can be used not only for wastewater analysis but also for surface and drinking water analysis as shown below. For the latter, the German Environment Agency (UBA) suggests limit values for DCF of $1.75 \mu \mathrm{g} / \mathrm{L}$ (guidance value) and $20 \mu \mathrm{g} / \mathrm{L}$ (technical action value) [48]. Both these values lie well within the range of this assay. Therefore, it could serve as a quick method to estimate the safety of drinking water. Moreover, with a time of analysis of around 45 min accompanied by the high sample throughput, the magnetic bead-based assay provides analytical results much faster than HPLC-MS and conventional immunoassays like ELISA.

\section{Analysis of water samples}

In order to demonstrate the practicability of the assay for analyzing the concentration of diclofenac in water, six different water samples were taken and analyzed directly as well as at three different spiking levels (24 samples in total). The results were confirmed by LC-MS/MS analysis (Table S1).

Comparison of DCF concentrations determined by MBBA and LC-MS/MS showed good correlation over the covered concentration range from $500 \mathrm{ng} / \mathrm{L}$ to $100 \mu \mathrm{g} / \mathrm{L}$ with few larger deviations occurring at elevated concentration values (Fig. 5, Fig. S8, and Table S4). No false negative results were observed demonstrating that contamination of water with DCF could be detected reliably. On the other hand, only one false positive result occurred within the measurement range of the assay (P9) and another one 


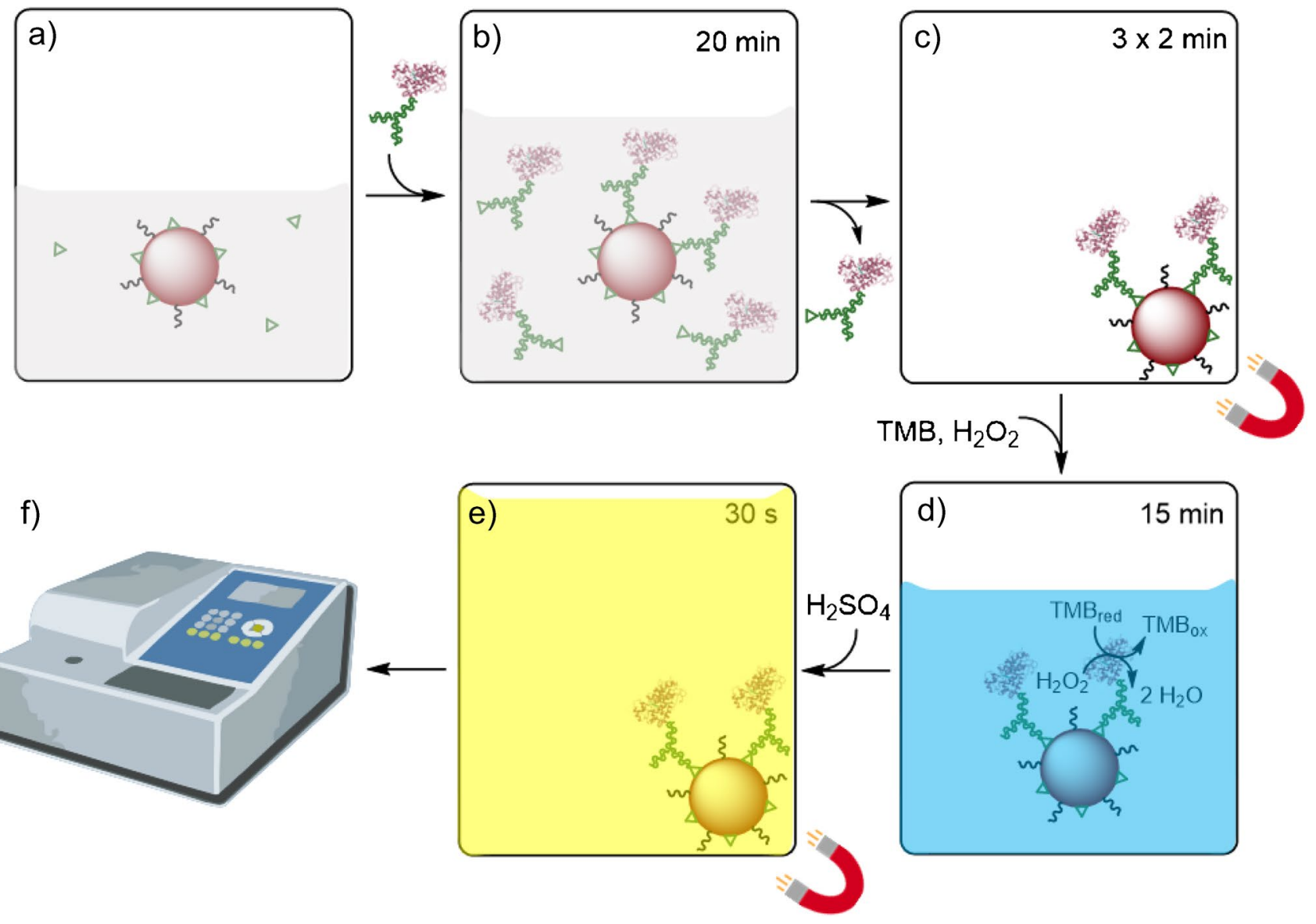

Fig. 3 Schematic illustration of each assay step and the respective time frame. a Water sample containing DCF (green triangles) is added to the suspension of DCF-coupled magnetic beads in assay buffer. b HRP-labeled anti-DCF antibody is added and incubated with the sample and beads for competitive binding for $20 \mathrm{~min}$. c Washing is performed by holding the beads with a magnet, removing the supernatant, and adding washing buffer (repeated twice). d Substrate

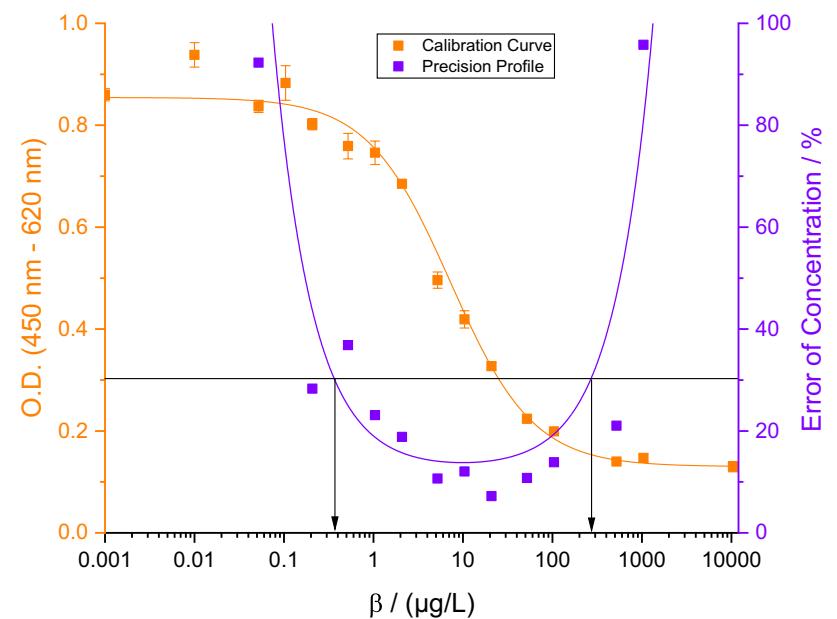

Fig. 4 Calibration curve of the optimized assay (orange) and precision profile (purple); $n=6$; error bars represent single standard deviation. The arrows indicate lower and upper limits of detection, and thus the measurement range of the assay ( $400 \mathrm{ng} / \mathrm{L}-300 \mu \mathrm{g} / \mathrm{L})$ solution containing TMB and hydrogen peroxide is added and incubated with the particles for 15 min while blue color develops upon substrate oxidation. e The oxidation reaction is stopped by addition of sulfuric acid with the color of the solution changing to yellow, and beads are immobilized on the side of the well for the following $\mathbf{f}$ absorption measurement in a spectrophotometer

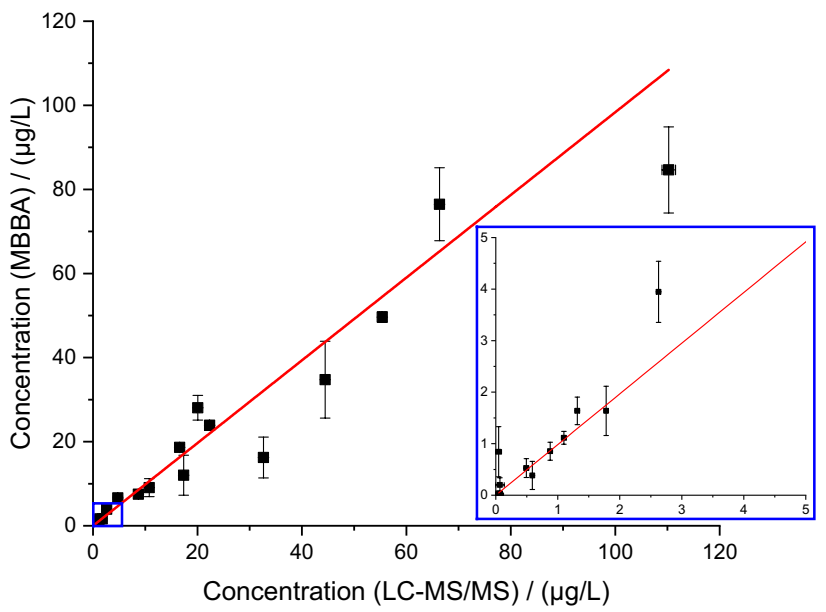

Fig. 5 Correlation of DCF concentrations determined by MBBA $(n=3)$ and LC-MS/MS analysis $(n=4)$; error bars represent single standard deviation (regression line parameters: slope $m=0.98 \pm 0.03$, $R^{2}=0.976$ ) 


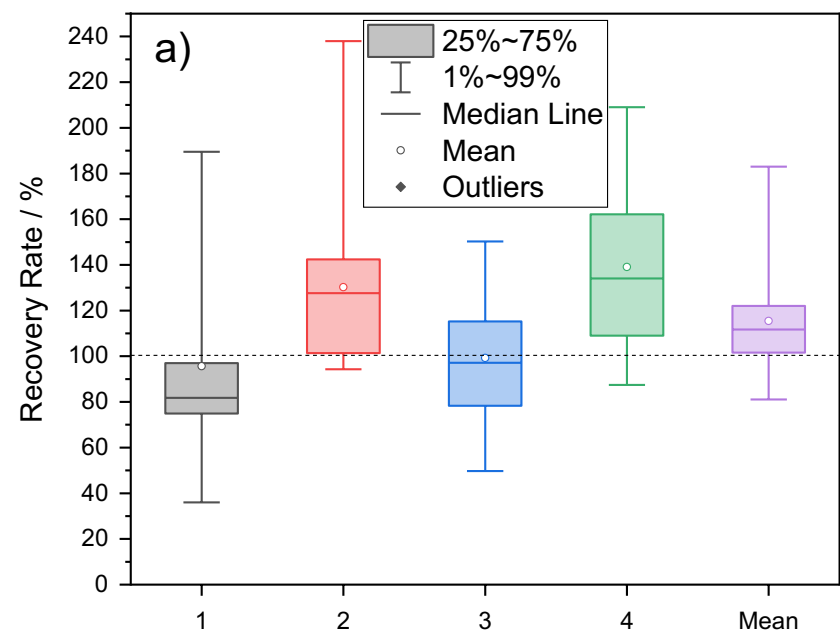

Fig. 6 a Recovery rates (without blanks, $n=19$ ) in four independent analyses and mean of all four measurements for water samples compared to LC-MS/MS reference. b Intra-assay variations of four

outside of the measurement range (P17) with a determined concentration (203 $\mathrm{ng} / \mathrm{L})$ below the actual LOD of the assay. Apart from that, the MBBA was able to detect contamination of the unspiked surface water sample (Teltowkanal) with approx. $500 \mathrm{ng} / \mathrm{L}$ DCF which was confirmed by LC-MS/ MS. In accordance with this, higher concentrations were found for all three corresponding spiked surface water samples by both methods. Compared with the results of earlier analyses of the same water in 2016 (DCF concentrations: 2.1 and $1.9 \mu \mathrm{g} / \mathrm{L}$ ) [21], the concentration determined here appears significantly lower but may be dependent on the sampling site. It is known that an inlet for treated wastewater is further downstream from the sampling site so that higher concentrations of DCF should be found there.

In order to evaluate the accuracy of the assay, recovery rates were determined with respect to LC-MS/MS reference measurements. In four different analyses of the same 24 samples, mean recovery rates were found in a range from 96 to $139 \%$ with overestimations at low concentration levels shifting the data to higher values (Fig. 6a, Tables S2-S6).

Regarding precision, the mean intra-assay variations of the same four sample analyses ranged from 13 to $25 \%$ (Fig. 6b, Tables S2-S6). Higher relative variations were found mainly for low concentration samples. As expected, inter-assay variances were slightly higher with a mean CV of $34 \%$ where single false-positive results of blank samples stretched the data range to higher values. Overall, accuracy and precision of the assay appear reasonable for quick estimations of the DCF concentrations in the various tested water samples with the main strengths of the method lying in the high sample throughput, the broad measurement range, short analysis times, cost-effectiveness, and the low equipment expenditure.

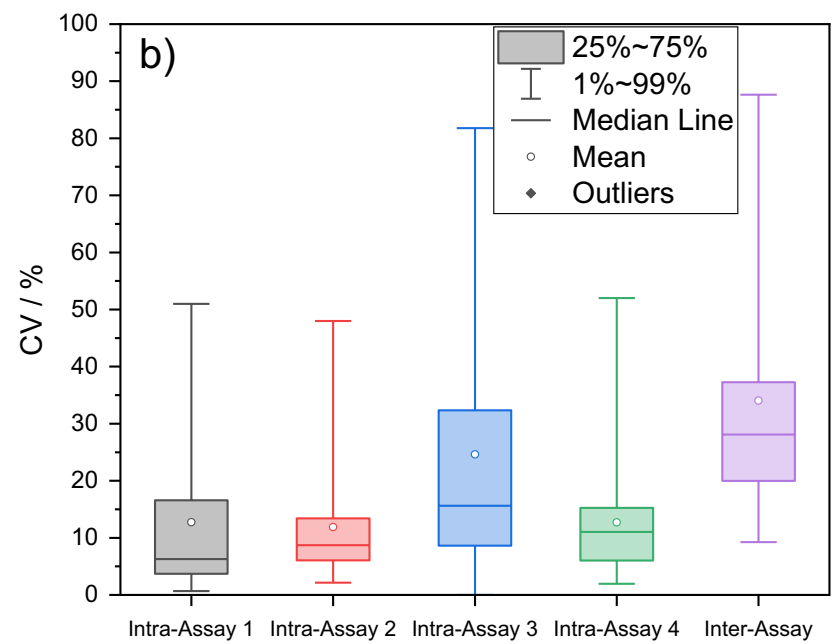

independent sample analyses in triplicate each $(n=3, m=24)$ and inter-assay variation of the mean of these four measurements $(n=4$, $m=24$ )

\section{Conclusion}

The developed MBBA proved to be a fast and reliable method to determine the DCF concentration in water samples with an LOD of $400 \mathrm{ng} / \mathrm{L}$. Due to the wide measurement range and short analysis time, the MBBA possesses distinct advantages over other immunoassays such as ELISA, which is more time-consuming and in case of DCF less sensitive using the same antibody [24, 25]. This might be the case for other anti-DCF antibodies as well and appears worth investigating [22, 23]. In terms of accuracy and precision, the assay shows satisfactory mean recovery rates of $100-140 \%$ in relation to reference analysis by LC-MS/MS, and typical coefficients of variation of 10-25\% (intra-assay) and 30\% (inter-assay). The MBBA only requires manual washing steps, using a pipette, and therefore does not require a microplate washer which makes its implementation easier and enhances its field portability. With this, the assay provides a quick and easy method to assess contamination of water and in this context the safety of its use as a source of drinking water.

Prospectively, the assay principle can be transferred to other analytes with the same improvement in terms of analysis time and sensitivity as for DCF, having the potential to replace ELISA as the standard technique in immunoanalysis. Incorporation of the magnetic beads into a lateral flow system appears feasible as well and represents another future application of our magnetic beads. As shown previously, changing the detection mode from optical to electrochemical detection is also possible which allows for further miniaturization of the system and mobile testing [49]. Beyond that, the use of magnetic beads will also enable automation and implementation of the assay into autonomous sensors for 
possible on-site analysis. Our efforts in this direction focus on developing an integrated diagnosis system for pharmaceutical contaminants directly in water supply pipes.

Supplementary Information The online version contains supplementary material available at https://doi.org/10.1007/s00216-021-03778-7.

Acknowledgements We thank the Indo-German Science and Technology Centre (IGSTC) and Federal Ministry for Education and Research (BMBF) for funding of the associated project IDC-Water (Integrated Diagnostics of Contaminants in Water supply and management systems) as well as the project partners for the successful collaboration.

We further thank Soraya Höfs (BAM) for support in water sampling and Valerie Jaut (BAM) for lab assistance.

Author contribution Conceptualization: Alexander Ecke. Methodology: Alexander Ecke. Formal analysis: Alexander Ecke and Tanja Westphalen. Investigation: Alexander Ecke, Tanja Westphalen and Jane Hornung. Validation: Alexander Ecke and Tanja Westphalen. Resources: Michael Voetz and Rudolf J. Schneider. Data curation: Alexander Ecke. Visualization: Alexander Ecke. Writing-original draft preparation: Alexander Ecke. Writing-review and editing: Tanja Westphalen, Jane Hornung, Michael Voetz and Rudolf J. Schneider. Supervision: Michael Voetz and Rudolf J. Schneider. Project administration: Michael Voetz and Rudolf J. Schneider. Funding acquisition: Michael Voetz and Rudolf J. Schneider. All the authors have read and agreed to the published version of the manuscript.

Funding Open Access funding enabled and organized by Projekt DEAL. This work contributes to the project IDC-Water co-funded by the Indo-German Science and Technology Centre (IGSTC) and Federal Ministry for Education and Research (BMBF), grant number FKZ 01DQ18003A.

Data availability Supplementary Material is available...

Code availability Not applicable.

\section{Declarations}

Conflict of interest The authors declare no competing interests.

Open Access This article is licensed under a Creative Commons Attribution 4.0 International License, which permits use, sharing, adaptation, distribution and reproduction in any medium or format, as long as you give appropriate credit to the original author(s) and the source, provide a link to the Creative Commons licence, and indicate if changes were made. The images or other third party material in this article are included in the article's Creative Commons licence, unless indicated otherwise in a credit line to the material. If material is not included in the article's Creative Commons licence and your intended use is not permitted by statutory regulation or exceeds the permitted use, you will need to obtain permission directly from the copyright holder. To view a copy of this licence, visit http://creativecommons.org/licenses/by/4.0/.

\section{References}

1. Kantor TG. Use of diclofenac in analgesia. Am J Med. 1986;80(4, Supplement 2):64-9. https://doi.org/10.1016/0002-9343(86) 90083-5.
2. Altman R, Bosch B, Brune K, Patrignani P, Young C. Advances in NSAID development: evolution of diclofenac products using pharmaceutical technology. Drugs. 2015;75(8):859-77. https:// doi.org/10.1007/s40265-015-0392-z.

3. McGettigan P, Henry D. Use of non-steroidal anti-inflammatory drugs that elevate cardiovascular risk: an examination of sales and essential medicines lists in low-, middle-, and high-income countries. PLOS Med. 2013;10(2):e1001388. https://doi.org/10. 1371/journal.pmed.1001388.

4. Bruun Kristensen K, Karlstad Ø, Martikainen JE, Pottegård A, Wastesson JW, Zoega H, Schmidt M. Nonaspirin nonsteroidal antiinflammatory drug use in the Nordic countries from a cardiovascular risk perspective, 2000-2016: a drug utilization study. Pharmacotherapy. 2019;39(2):150-60. https://doi.org/10.1002/ phar.2217.

5. Vieno N, Sillanpää M. Fate of diclofenac in municipal wastewater treatment plant - a review. Environ Int. 2014;69:28-39. https:// doi.org/10.1016/j.envint.2014.03.021.

6. Zhang Y, Geißen S-U, Gal C. Carbamazepine and diclofenac: removal in wastewater treatment plants and occurrence in water bodies. Chemosphere. 2008;73(8):1151-61. https://doi.org/10. 1016/j.chemosphere.2008.07.086.

7. Schwaiger J, Ferling H, Mallow U, Wintermayr H, Negele RD. Toxic effects of the non-steroidal anti-inflammatory drug diclofenac: part I: histopathological alterations and bioaccumulation in rainbow trout. Aquat Toxicol. 2004;68(2):141-50. https:// doi.org/10.1016/j.aquatox.2004.03.014.

8. Triebskorn R, Casper H, Heyd A, Eikemper R, Köhler HR, Schwaiger J. Toxic effects of the non-steroidal anti-inflammatory drug diclofenac: part II. Cytological effects in liver, kidney, gills and intestine of rainbow trout (Oncorhynchus mykiss). Aquat Toxicol. 2004;68(2):151-66. https://doi.org/10.1016/j. aquatox.2004.03.015.

9. Oaks JL, Gilbert M, Virani MZ, Watson RT, Meteyer CU, Rideout BA, Shivaprasad HL, Ahmed S, Chaudhry MJI, Arshad M, Mahmood S, Ali A, Khan AA. Diclofenac residues as the cause of vulture population decline in Pakistan. Nature. 2004;427(6975):630-3. https://doi.org/10.1038/nature02317.

10. Saini M, Taggart MA, Knopp D, Upreti S, Swarup D, Das A, Gupta PK, Niessner R, Prakash V, Mateo R, Cuthbert RJ. Detecting diclofenac in livestock carcasses in India with an ELISA: a tool to prevent widespread vulture poisoning. Environ Pollut. 2012;160:11-6. https://doi.org/10.1016/j.envpol.2011. 09.011.

11. Bonnefille B, Gomez E, Courant F, Escande A, Fenet H. Diclofenac in the marine environment: a review of its occurrence and effects. Mar Pollut Bull. 2018;131:496-506. https://doi.org/ 10.1016/j.marpolbul.2018.04.053.

12. Sathishkumar P, Meena RAA, Palanisami T, Ashokkumar V, Palvannan T, Gu FL. Occurrence, interactive effects and ecological risk of diclofenac in environmental compartments and biota - a review. Sci Total Environ. 2020;698:134057. https://doi.org/10. 1016/j.scitotenv.2019.134057.

13. Commission Implementing Decision (EU) 2015/495 of 20 March 2015 establishing a watch list for Union-wide monitoring in the field of water policy pursuant to Directive 2008/105/EC of the European Parliament and of the Council. Official Journal of the European Union2015. p. 40-2.

14. Proposal for a Directive of the European Parliament and of the Council amending Directives 2000/60/EC and 2008/105/EC as regards priority substances in the field of water policy. European Commission; 2012. p. COM/2011/0876 final - 2011/0429 (COD).

15. Huber C, Preis M, Harvey PJ, Grosse S, Letzel T, Schröder P. Emerging pollutants and plants - metabolic activation of diclofenac by peroxidases. Chemosphere. 2016;146:435-41. https://doi.org/10.1016/j.chemosphere.2015.12.059. 
16. Jewell KS, Falås $\mathrm{P}$, Wick A, Joss A, Ternes TA. Transformation of diclofenac in hybrid biofilm-activated sludge processes. Water Res. 2016;105:559-67. https://doi.org/10.1016/j.watres.2016.08. 002.

17. Rigobello ES, Di Bernardo DA, Di Bernardo L, Vieira EM. Removal of diclofenac by conventional drinking water treatment processes and granular activated carbon filtration. Chemosphere. 2013;92(2):184-91. https://doi.org/10.1016/j.chemosphere.2013. 03.010.

18. Langenhoff A, Inderfurth N, Veuskens T, Schraa G, Blokland M, Kujawa-Roeleveld K, Rijnaarts H. Microbial removal of the pharmaceutical compounds ibuprofen and diclofenac from wastewater. BioMed Res Int. 2013;2013:325806. https://doi.org/10.1155/ 2013/325806.

19. Rosset M, Weidlich Sfreddo L, Navarro Hidalgo GE, PerezLopez OW, Amaral FL. Adsorbents derived from hydrotalcites for the removal of diclofenac in wastewater. Appl Clay Sci. 2019;175:150-8. https://doi.org/10.1016/j.clay.2019.04.014.

20 Angosto JM, Roca MJ, Fernández-López JA. Removal of diclofenac in wastewater using biosorption and advanced oxidation techniques: comparative results. Water. 2020;12(12):3567. https://doi.org/10.3390/w12123567.

21. Schmidt S, Hoffmann H, Garbe L-A, Schneider RJ. Liquid chromatography-tandem mass spectrometry detection of diclofenac and related compounds in water samples. J Chromatogr A. 2018;1538:112-6. https://doi.org/10.1016/j.chroma.2018.01.037.

22. Deng A, Himmelsbach M, Zhu Q-Z, Frey S, Sengl M, Buchberger W, Niessner R, Knopp D. Residue analysis of the pharmaceutical diclofenac in different water types using ELISA and GC-MS. Environ Sci Technol. 2003;37(15):3422-9. https://doi.org/10. 1021/es0341945.

23. Huebner M, Weber E, Niessner R, Boujday S, Knopp D. Rapid analysis of diclofenac in freshwater and wastewater by a monoclonal antibody-based highly sensitive ELISA. Anal Bioanal Chem. 2015;407(29):8873-82. https://doi.org/10.1007/ s00216-015-9048-9.

24. Harrer A, Lang R, Grims R, Braitsch M, Hawranek T, Aberer W, Vogel L, Schmid W, Ferreira F, Himly M. Diclofenac hypersensitivity: antibody responses to the parent drug and relevant metabolites. PLoS ONE. 2010;5(10):e13707. https://doi.org/10. 1371/journal.pone.0013707.

25. Schmidt S. Hapten synthesis for the antibody-based detection of diclofenac in water samples [Dissertation]: Technische Universität Berlin; 2019.

26. Hlaváček A, Peterek M, Farka Z, Mickert MJ, Prechtl L, Knopp D, Gorris HH. Rapid single-step upconversion-linked immunosorbent assay for diclofenac. Microchim Acta. 2017;184(10):4159-65. https://doi.org/10.1007/s00604-017-2456-0.

27. Raysyan A, Moerer R, Coesfeld B, Eremin SA, Schneider RJ. Fluorescence polarization immunoassay for the determination of diclofenac in wastewater. Anal Bioanal Chem. 2021;413(4):9991007. https://doi.org/10.1007/s00216-020-03058-w.

28. Carl P, Sarma D, Gregório BJR, Hoffmann K, Lehmann A, Rurack $\mathrm{K}$, Schneider RJ. Wash-free multiplexed mix-and-read suspension array fluorescence immunoassay for anthropogenic markers in wastewater. Anal Chem. 2019;91(20):12988-96. https://doi.org/ 10.1021/acs.analchem.9b03040.

29. Nguyen TTK, Vu TT, Anquetin G, Tran HV, Reisberg S, Noël V, Mattana G, Nguyen QV, Dai Lam T, Pham MC, Piro B. Enzymeless electrochemical displacement heterogeneous immunosensor for diclofenac detection. Biosens Bioelectron. 2017;97:246-52. https://doi.org/10.1016/j.bios.2017.06.010.

30. Chen W, Zhu Q, Tang Q, Zhao K, Deng A, Li J. Ultrasensitive detection of diclofenac based on electrochemiluminescent immunosensor with multiple signal amplification strategy of palladium attached graphene oxide as bioprobes and ceria doped zinc oxide as substrates. Sensor Actuat B-Chem. 2018;268:411-20. https:// doi.org/10.1016/j.snb.2018.04.106.

31. Hu L, Zheng J, Zhao K, Deng A, Li J. An ultrasensitive electrochemiluminescent immunosensor based on graphene oxide coupled graphite-like carbon nitride and multiwalled carbon nanotubes-gold for the detection of diclofenac. Biosens Bioelectron. 2018;101:260-7. https://doi.org/10.1016/j.bios.2017.10. 043.

32. Shi J, Xu M, Tang Q, Zhao K, Deng A, Li J. Highly sensitive determination of diclofenac based on resin beads and a novel polyclonal antibody by using flow injection chemiluminescence competitive immunoassay. Spectrochim Acta A. 2018;191:1-7. https://doi.org/10.1016/j.saa.2017.09.068.

33. Kaewwonglom N, Oliver M, Cocovi-Solberg DJ, Zirngibl K, Knopp D, Jakmunee J, Miró M. Reliable sensing platform for plasmonic enzyme-linked immunosorbent assays based on automatic flow-based methodology. Anal Chem. 2019;91(20):132607. https://doi.org/10.1021/acs.analchem.9b03855.

34. Steinke N, Döring S, Wuchrer R, Kroh C, Gerlach G, Härtling T. Plasmonic sensor for on-site detection of diclofenac molecules. Sensor Actuat B-Chem. 2019;288:594-600. https://doi.org/10. 1016/j.snb.2019.02.069.

35. Wang C, Jiang T, Zhao K, Deng A, Li J. A novel electrochemiluminescent immunoassay for diclofenac using conductive polymer functionalized graphene oxide as labels and gold nanorods as signal enhancers. Talanta. 2019;193:184-91. https://doi.org/ 10.1016/j.talanta.2018.09.103.

36. Choi J-W, Oh KW, Thomas JH, Heineman WR, Halsall HB, Nevin JH, Helmicki AJ, Henderson HT, Ahn CH. An integrated microfluidic biochemical detection system for protein analysis with magnetic bead-based sampling capabilities. Lab Chip. 2002;2(1):27-30. https://doi.org/10.1039/B107540N.

37. Hervás M, López MÁ, Escarpa A. Simplified calibration and analysis on screen-printed disposable platforms for electrochemical magnetic bead-based inmunosensing of zearalenone in baby food samples. Biosens Bioelectron. 2010;25(7):1755-60. https://doi. org/10.1016/j.bios.2009.12.031.

38. Kwon Y, Hara CA, Knize MG, Hwang MH, Venkateswaran KS, Wheeler EK, Bell PM, Renzi RF, Fruetel JA, Bailey CG. Magnetic bead based immunoassay for autonomous detection of toxins. Anal Chem. 2008;80(22):8416-23. https://doi.org/10.1021/ ac8010044.

39. Hendrickson OD, Chertovich JO, Zherdev AV, Sveshnikov PG, Dzantiev BB. Ultrasensitive magnetic ELISA of zearalenone with pre-concentration and chemiluminescent detection. Food Control. 2018;84:330-8. https://doi.org/10.1016/j.foodcont.2017.08.008.

40. Kantiani L, Farré M, Asperger D, Rubio F, González S, López de Alda MJ, Petrović M, Shelver WL, Barceló D. Triclosan and methyl-triclosan monitoring study in the northeast of Spain using a magnetic particle enzyme immunoassay and confirmatory analysis by gas chromatography-mass spectrometry. J Hydrol. 2008;361(1):1-9. https://doi.org/10.1016/j.jhydrol.2008.07.016.

41. Wang Y-K, Wang Y-C, Wang H, Ji W-H, Sun J-H, Yan Y-X. An immunomagnetic-bead-based enzyme-linked immunosorbent assay for sensitive quantification of fumonisin B1. Food Control. 2014;40:41-5. https://doi.org/10.1016/j.foodcont.2013.11.025.

42. Zhao F, Shen Q, Wang H, Han X, Yang Z. Development of a rapid magnetic bead-based immunoassay for sensitive detection of zearalenone. Food Control. 2017;79:227-33. https://doi.org/ 10.1016/j.foodcont.2017.03.051.

43. Deng Q, Qiu M, Wang Y, Lv P, Wu C, Sun L, Ye R, Xu D, Liu Y, Gooneratne R. A sensitive and validated immunomagnetic-bead based enzyme-linked immunosorbent assay for analyzing total T-2 (free and modified) toxins in shrimp tissues. Ecotox Environ Safe. 2017;142:441-7. https://doi.org/10.1016/j.ecoenv.2017.04.037. 
44. Xin T-B, Wang X, Jin H, Liang S-X, Lin J-M, Li Z-J. Development of magnetic particle-based chemiluminescence enzyme immunoassay for the detection of $17 \beta$-estradiol in environmental water. Appl Biochem Biotech. 2009;158(3):582-94. https://doi. org/10.1007/s12010-008-8356-3.

45. Huergo LF, Selim KA, Conzentino MS, Gerhardt ECM, Santos ARS, Wagner B, Alford JT, Deobald N, Pedrosa FO, de Souza EM, Nogueira MB, Raboni SM, Souto D, Rego FGM, Zanette DL, Aoki MN, Nardin JM, Fornazari B, Morales HMP, Borges VA, Nelde A, Walz JS, Becker M, Schneiderhan-Marra N, Rothbauer U, Reis RA, Forchhammer K. Magnetic bead-based immunoassay allows rapid, inexpensive, and quantitative detection of human SARS-CoV-2 antibodies. ACS Sens. 2021;6(3):703-8. https://doi. org/10.1021/acssensors.0c02544.

46. Wilson MB, Nakane PP. Recent developments in the periodate method of conjugating horseradish peroxidase (HRP) to antibodies. In: Knapp W, Holubar K, Wick G, editors. Immunofluorescence and related staining techniques. Amsterdam: Elsevier/North Holland Biomedical; 1978. p. 215-24.
47. Ekins RP. The precision profile: its use in assay design, assessment and quality control. In: Hunter WM, Corrie JET, editors. Immunoassays for clinical chemistry. 2nd ed. Edinburgh: Churchill Livingstone; 1983. p. 76-105.

48 Dieter HH. Grenzwerte, Leitwerte, Orientierungswerte, Maßnahmenwerte - Aktuelle Definitionen und Höchstwerte. DessauRoßlau: Umweltbundesamt; 2011.

49. Höfs S, Hülagü D, Bennet F, Carl P, Flemig S, Schmid T, Schenk JA, Hodoroaba V-D, Schneider RJ. Electrochemical immunomagnetic ochratoxin A sensing: steps forward in the application of 3,3',5,5'-tetramethylbenzidine in amperometric assays. ChemElectroChem. 2021;8(13):2597-606. https://doi.org/10.1002/celc. 202100446

Publisher's note Springer Nature remains neutral with regard to jurisdictional claims in published maps and institutional affiliations. 